\title{
Lidocaine intoxication in axillary block: similar pharmaceutical form, different concentration
}

\author{
Zeynel Abidin Erbesler ${ }^{1}$, Gulsah Karaoren ${ }^{2}$, Recai Dagli ${ }^{1}$, Vedat Cakirtekin ${ }^{3}$ \\ ${ }^{1}$ Department of Anesthesiology, Ahi Evran University, Training And Research Hospital, Kirsehir, Turkey; \\ 2Department of Anesthesiology, Umraniye Training and Research Hospital, Istanbul, Turkey; \\ ${ }^{3}$ Department of Anesthesiology, Prof. Dr. Celal Ertug Etimesgut Hospital, Ankara, Turkey
}

\begin{abstract}
Local anesthetic intoxication is a medical emergency with high mortality. These drugs have not spesific antidotes, quick differential diagnosis and supportive treatment required in the case of exposure to toxic doses. We report the complications and anesthetic management of a patient who was scheduled for right carpal tunnel syndrome surgery under regional anesthesia, but mistakenly received injection of $140 \mathrm{mg}$ procaine added to $10 \% 10 \mathrm{~mL}$ lidocaine $(10 \mathrm{~mL}=1000 \mathrm{mg})$ instead of $2 \%$ lidocaine $(10 \mathrm{~mL}=200 \mathrm{mg})$ as part of an axillary plexus blockade.
\end{abstract}

Key words: Axillary blokage; intoxication; lidocaine.

T oxic reactions are among the most prevalent causes of medical emergencies [1]. Development of regional techniques, introduction of new long-acting local anesthetics into clinical use in the practice of anesthesia within the last 20 years, raised awareness among physicians, and patients about the use of regional anesthesia have resulted in increased popularity, and applicability of regional anesthesia. Despite technologies which widen safety margins of regional anesthesia including use of bedside ultrasound which reveals the anatomy of the site of application, and use of peripheral nerve stimulator which directly determines the nerve to be targeted, still intoxications related to local anesthetics in applications of regional anesthesia can be seen as a serious, and important adverse effects with incidence rates ranging between 0.01 , and $0.2 \%$ of the cases [2].

Local anesthetics used in the practice of regional anesthesia have usually an amide component, and they induce $\mathrm{Na}$ channel blockade in cell membranes, and thus prevent transmission of impulses by way of axons. Lidocaine is an amide group local anesthetic which is preferred in relatively shorter surgical interventions, infiltration anesthesia, extremity blocks, topical anesthesia, and regional intravenous anesthesia (RIVA) with its higher potency, rapid onset, and termination of its action. Its intoxications when used in local anesthesia, emerge frequently during inadvertent intravenous administration of the drug

Received: September 18, 2014 Accepted: November 14, 2014 Online: January 24, 2015

Correspondence: Dr. Zeynel Abidin ERBESLER. Ahi Evran Universitesi Egitim Arastirma Hastanesi, Kervansaray Mahhallesi, 2019. Sokak, No:1, Kirsehir, Turkey. 
in applications of central or peripheral blockade, unnecessarily higher drug dosage, and rapid systemic absorption of the drug. Though central nervous system is firstly, and most frequently affected in local anesthesic intoxications, mortality rates increase due to cardiovascular system involvement. Cardiovascular effects can manifest themselves as enlarged QRS complex due to prolonged $\mathrm{Na}$ channel blockade in diastole, prolonged PR interval, AV blocks, and related dangerous arrhytmias. However its central effects appear secondary to cortical stimulation. Early manifestations of cortical stimulation including relatively mild symptoms as metallic taste in the mouth, numbness, disorientation, tinnitus, paresthesia, ataxia, dysarthria, nystagmus, and dose related serious symptoms of cortical stimulation as convulsions, respiratory system depression, serious arrhytmias, deep cardiovascular collapse, and coma can develop $[2,3]$.

In our article, complications and anesthetic management of a patient who was scheduled for right carpal tunnel syndrome surgery under regional anesthesia, and mistakenly received injection of 140 $\mathrm{mg}$ procaine added to $10 \% 10 \mathrm{~mL}$ lidocaine $(10$ $\mathrm{mL}=1000 \mathrm{mg})$ instead of $2 \%$ lidocaine $(10 \mathrm{~mL}=200$ $\mathrm{mg}$ ) as part of an axillary plexus blockade.

\section{CASE REPORT}

A 57-year-old-male patient $165 \mathrm{~cm}$ tall, and weighing $68 \mathrm{~kg}$ in the ASA 1 risk group because of numbness of his left wrist. The biochemical parameters of the patient who was scheduled for operation under regional anesthesia with the diagnosis of carpal tunnel syndrome were as follows; $\mathrm{Hb}: 14.0 \mathrm{mg} /$ dL, Htc:43.0\%, Plt:229000/ $\mathrm{mm}^{3}$, WBC:6000/ $\mathrm{mm}^{3}$, FBG:100 mg/dL, BUN:2817 mg/dL, Creatinine:0.7 mg/dL, AST:20.72 mg/dL, and ALT:12.45 mg/dL. His electrocardiogram (EKC) revealed a HR of $70 \mathrm{bpm}$ with normal sinus rhythm.

Preoperatively the patient was informed about axillary nerve blockade, and his written informed consent was obtained. He didn't receive any preoperative premedication, and in the operating room, his standard $\mathrm{EKG}$, peripheral $\mathrm{O}_{2}$ saturation $\left(\mathrm{SpO}_{2}\right)$, and noninvasive blood pressure (NIBP) were monitores. Using a $18 \mathrm{G}$ branule a vein on the back of his left hand was punctured, and $0.09 \% \mathrm{NaCl}$ infusion at a rate of $200 \mathrm{ml} / \mathrm{hr}$ was initiated. Right arm to be operated was positioned at $90 \mathrm{o}$ abduction with the torso, and forearm was flexed $90^{\circ}$. After cleansing the surgical field with a sterile antibacterial solution, the site was covered with sterile drape, and a single injection was made with a $22 \mathrm{G}$ x $50 \mathrm{~mm}$ needle (Stimuplex ${ }^{\oplus}$ Braun, Melsungen, Germany). Retrograde blood was not observed during negative aspiration.

Using a peripheral nerve stimulator (Stimuplex A; B.Braun Melsungen AG, B.Braun Medical AG $\mathrm{CH}-6021$, Germany) at an intensity of $1.5 \mathrm{~mA}$ the nerve was localized. When the intensity of the electrical current was reduced to $0.5 \mathrm{~mA}$, nervous stimuli were observed which made us to think that we were on the innervation site of the nerve to be blocked. Then $40 \mathrm{~mL}$ anesthetic solution preprepared by anesthesia technician which we thought to be our routinely used mixture i.e. [ $20 \mathrm{~mL} 1 \%$ lidocaine (2 ampoules of $2 \%$ lidocaine, and $10 \mathrm{~mL}$ $\mathrm{NaCl} 0.09 \%)$ and $20 \mathrm{~mL} \mathrm{1 \%}$ prilocaine $(10 \mathrm{~mL} 2 \%$ prilocaine, and $10 \mathrm{mL0}, 09 \% \mathrm{NaCl}$ )] was injected to the patient with negative suctions after each application of $5 \mathrm{~mL}$. Injection site was compressed for 5 minutes. Nearly 10 minutes later the patient felt numbness on his tongue, irritability, restlessness, agitation, he uttered meaningless words, and moved his arms, and legs senselessly. Decreased peripheral oxygen saturation and presence of peripheral cyanosis led us to make an initial diagnosis of methemoglobinemia, and supportive $\mathrm{O}_{2}$ therapy was initiated via oxygen mask at a rate of 6 lt per minute. We couldn't measure methemoglobin levels because of lack of necessity facilities. Arterial blood gas measurements were as follows. $\mathrm{pH}: 7.43 \mathrm{pO}_{2}: 60.1$, and $\mathrm{pCO}_{2}: 44.0$. Respiratory distress of the patient increased, and deepened, with a drop in his $\mathrm{SpO}_{2}$ to 76 , was intubated under $1 \mathrm{mg} / \mathrm{kg}$ propofol, $1 \mu /$ $\mathrm{kg}$ fentanyl, and $0.5 \mathrm{mg} \cdot \mathrm{kg}^{-1}$ rocuronium anesthesia to enjure the patency of his airway. For the postintubation maitenance of anesthesia 50 oxygen nitrogen, and 1 mac sevoflurane were used. Following induction of anesthesia, hypotension (NIBP: 60/40 $\mathrm{mmHg}$ ), and bradycardia (HR:40 bpm) developed which required administration of $0.5 \mathrm{mg}$ atropin, and intermittent IV injections of ephedrine (total dose $30 \mathrm{mg}$ ). When his health state was stabilized, NIBP values improved, and his HR dropped to $70 \mathrm{bpm}$ with $\mathrm{SpO}_{2} \div 95 \%$, he was amenable for surgery. At the end of the operation which lasted 
for nearly half an hour, the patient was awakened with injections of $10 \mu \mathrm{g} / \mathrm{kg}$ atropine, and $40 \mu \mathrm{g} / \mathrm{kg}$ neostigmine. Thoughy the patient still continued to articulate meaningless words, and make senseless movements, since he was more cooperative we transferred the patient into the intensive care unit.

When we discerned that in place of $2 \%$ lidocaine ampoule which we always requested as a local anesthetic from the pharmacy, 10\% lidocaine ampoule was sent, and anesthetic mixture was prepared without checking whether it was $2 \%$ lidocaine, we made the diagnosis of local anesthetic intoxication related to wrong formulation of lidocaine rather than methemoglobinemia

During 24-hour monitorization in the intensive care unit his hemodynamic parameters were stable, and his complaints resolved. Then the patient was traansferred to his service with relevant recommendations.

\section{DISCUSSION}

Ninety-eight percent of systemic reactions that might develop against local anesthetic agents are related to higher plasma concentrations of the drugs used. Higher plasma concentrations can be observed when doses higher than the maximum daily doses are used or in cases of unwanted intravascular injections during central or peripheral nerve blocks [4]. Lidocaine is a local anesthetic with a amide component which induces $\mathrm{Na}$ channel blockade in nerve cell membranes. Because of its higher potency, lesser systemic toxic reactions, its safety in IV use unless toxic doses are not exceeded, lidocaine is frequently used local anesthetic in anesthesia practice. Lidocaine at doses exceeding $4 \mathrm{mg} / \mathrm{kg}$, and doses above $7.5 \mathrm{mg} / \mathrm{kg}$ of its combined form with adrenaline used in local anesthesia have toxicity effects [1].

In CNS toxicity relaated to local anesthetics, firstly excitatory, then depressive symptoms become evident. Presence of hypoxia, hypercapnia, and acidosis further facilitates development of convulsion. Besides cardiovascular collapse can be seen because of the impact of local anesthetic on vascular smooth muscle resulting in vasodilation, and bradycardia due to its direct effect on myocardium. Symptoms of cardiac toxicity are more frequently seen in patients with a history of cardiovascular disease [5].
In our case occurrence of mild hypoxia, and cyanosis at the onset made us to think of the development of methemoglobinemia related to prilocaine injection. Regression of cyanosis after delivery of $100 \% \mathrm{O}_{2}$ made us to drift away from the diagnosis of methemoglobinemia.

Local anesthetics can be marketed in many pharmaceuitical forms as cream, gel, lyposomal capsule, tablet, and spray. Tablet formulation of mexyletine, and tocainide which is a derivative of lidocaine have been used in antiarrhytmic, a nd neuropathic pains. Besides, $10 \%$ solution of lidocaine (Xylocain ${ }^{\circledR}$ pump spray) is used as an aerosol, and each puff contains $10 \mathrm{mg}$ lidocaine. In topical anesthesia EMLA ${ }^{\oplus}$ (2.5\% lidocaine, $2.5 \%$ prilocaine) cream has been applied.

Lidocaine solution is marketed in ampoules each containing $2 \%$, or $10 \%$ concentrations. Similar appearance of ampoules can easily result in erroneous applications. Injections of higher doses of lidocaine are one of the most frequent erroneous drug applications. Packaging of bolus, and concentrated dosage forms of these types of drugs is still problematic [6]. In our case, instead of injecting $2 \%$ lidocaine formulation which is used routinely for the purpose of peripheral blockade, the ampoule with similar appearance except for an extra yellow line on the neck of the ampoule which contained $10 \%$ lidocaine was inadvertently prepared for injection, and our patient received 5 -fold higher dose than our estimate.

Kudo et al. [7] presented a 76-year-old patient with known paroxysmal ventricular dysrhytmia who was injected $5 \mathrm{ml} 10 \%$ lidocaine $(599 \mathrm{mg})$ instead of $2.5 \mathrm{ml} 2 \%$ lidocaine $(50 \mathrm{mg}$ ) for the treatment of his dysrhytmia. They reported tonic-clonic convulsions immediately after high doses of lidocaine injection, then cardiac arrest developed. Despite initiation of resuscitation without delay the patient died.

Ludot et al. [8] planned knee surgery using posterior lumbar plexus block in a 13-year-old patient, and at 15. minute of lidocaine, and ropivacaine injection heart rate of the patient increased up to 150 $\mathrm{bpm}$, and ventricular tachycardia with a wide $\mathrm{QRS}$ complex emerged. Preoperatively measured arterial blood pressure $(88 / 45 \mathrm{mmHg})$ rised up to $12 / 92$, while $\mathrm{SpO}_{2}$ dropped from $99 \%$ to 92 percent. The patient was given $150 \mathrm{ml} \mathrm{IV}(3 \mathrm{mg} / \mathrm{kg}) 20 \%$ lipid emulsion (Medialipid 20\%, Braun, Germany) with 
the initial diagnosis of local anesthesic intoxication. At $2^{\text {nd }}$ minute of the infusion, her heart rate regressed to $100 \mathrm{bpm}$, and arterial blood pressure to $100 / 48 \mathrm{~mm} \mathrm{Hg}$, and $\mathrm{SpO}_{2}$ increased to 97 percent. After stabilization of her vital signs, and inability to detect any additional sign, we proceeded with the operation. The patient was discharged on postoperative 2. day without any sequalae.

Safe use of lipid emulsions in intoxications of local anesthetics was reported by Rosenblatt et al. [9] in the year 2006. In this presentation, brachial plexus blockade was applied using bupivacaine, and mepivacaine combination. After the blockade, cardiac arrest was developed in the patient, and cardiopulmonary resuscitation was initiated. The patient didn't respond to 20 minutes of resuscitation, then $100 \mathrm{ml} \mathrm{20 \%}$ Intralipid $^{\circledast}$ fat emulsion (Fresenius kabi, Uppsala, Sweeden) was administered through intravenous route, a little while after initiation of lipid therapy her hemodynamic parameters started to return to normal levels.

In the practice of anesthesia, lipid emulsions are marketed as total parenteral nutrition solutions and in formulations with propofol. However in the literature, clear-cut information about effective, and safe use of these emulsions in lipid rescue treatment is lacking [10]. In our case in consideration of potential beneficial effects of lipid solutions, we urgently requested these solutions from the pharmacy of our hospital, but we were unable to use them for the patient because of difficulties in its procurement.

Anesthesic pharmacotherapy requires constant care, and it is not exempt from erroneous applications. Erroneous applications, and unnecessarily higher doses can frequently lead to serious adverse effects, besides confusing infusion, and single dose applications, and dosage calculation errors can be also frequently seen. Blendon et al. [11] investigated faulty drug applications, reported physicians or family members (35\%), civilians (42\%) for these erroneous usage of drugs.

Even though literature information does not absolutely support, we think that in pharmacy departments of hospitals where day-care surgeries, and regional techniques are frequently applied, lipid solutions should be available for immediate use so as to protect the patients from adverse outcomes of drug use.

\section{CONCLUSION}

Finally, we think that preventive measurements including standardization, separation of different forms of the drugs (intrathecal, topical, and intravenous), drugs used in different dosages should be marketed in different coloured, and sized ampoules, controlled application of the drugs at every step of their usage, regular, meticulous, and updated pharmacological training of health personnel should be developed.

Conflict of Interest: No conflict of interest was declared by the authors.

Financial Disclosure: The authors declared that this study has received no financial support.

\section{REFERENCES}

1. Morgan GE. Clinical anesthesiology. Third edition. McGrawHill Companies 2002;297-8.

2. Ökten F. Hasdoğan M. Tarhan A. What is the importance of bupivacaine cardiotoxicity. Anestezi Dergisi 2010;18:189-93.

3. Bigger JT, Hoffman DF. Anti arrhythmic drugs.in: Gillman AG, Rall TW, Nies AS. Goodmanand Gillman: The pharmacologial basis of therapeutics 8th ed. Newyork: Pergamonpres; 1990. p. 857-61.

4. Miller RD. Local anaesthetics. Anesthesia Fourth edition. Chuchill Livingstone 1994;510-6.

5. Alfano SN, Leicht MJ, Skiendzielewski JJ. Lidocaine toxicity following subcutaneous administration. Ann Emerg Med 1984;13:465-7. CrossRef

6. Tokgöz O, Beyaz SG, Arrkanoğlu Z. Toxic reaction related to high dose lidocaine secondary to intravenous regional anesthesia. J ClinExpInvest 2010;1:119-21.

7. Kudo K, Nishida N, Kiyoshima A, Ikeda N. A fatal case of poisoning by lidocaine overdosage--analysis of lidocaine in formalin-fixed tissues: a case report. Med Sci Law 2004;44:266-71.

8. Ludot H, Tharin JY, Belouadah M, Mazoit JX, Malinovsky JM. Successful resuscitation after ropivacaine and lidocaine-induced ventricular arrhythmia following posterior lumbar plexus block in a child. Anesth Analg 2008;106:1572-4. CrossRef

9. Rosenblatt MA, Abel M, Fischer GW, Itzkovich CJ, Eisenkraft JB. Successful use of a $20 \%$ lipid emulsion to resuscitate a patient after a presumed bupivacaine-related cardiac arrest. Anesthesiology 2006;105:217-8. CrossRef

10. Weinberg G. Lipid infusion resuscitation for local anesthetic toxicity: proof of clinical efficacy. Anesthesiology 2006;105:7-8.

11. Blendon RJ, DesRoches CM, Brodie M, Benson JM, Rosen AB, Schneider E, et al. Views of practicing physicians and the public on medical errors. N Engl J Med 2002;347:1933-40. CrossRef 